\title{
Correction to: Allelopathic effects account for the inhibitory effect of field-pea
}

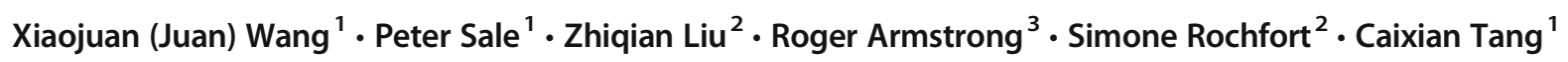

Published online: 14 August 2020

(C) Springer-Verlag GmbH Germany, part of Springer Nature 2020

Correction to: Biology and Fertility of Soils (2019) 55:649-659

https://doi.org/10.1007/s00374-019-01384-5

The name of the co-author of the article mentioned above was incorrectly presented. The correct name should have been "Peter Sale" instead of "Sale Peter". This is now presented correctly above.

The online version of the original article can be found at https://doi.org/ 10.1007/s00374-019-01384-5

Xiaojuan (Juan) Wang

Xiaojuan.Wang@latrobe.edu.au

1 Department of Animal, Plant and Soil Sciences, Centre for AgriBioscience, La Trobe University, Melbourne Campus, Bundoora, VIC 3086, Australia

2 Department of Economic Development, Jobs, Transport \& Resources, Centre for AgriBioscience, La Trobe University, Bundoora, VIC 3083, Australia

3 Department of Jobs, Precincts \& Resources, Horsham, VIC 3401, Australia 